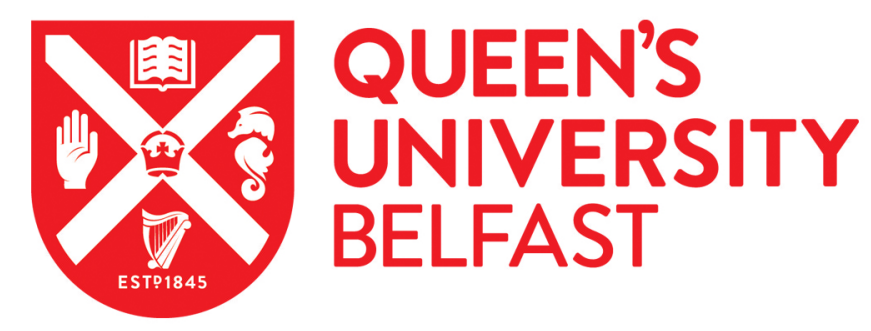

\title{
The Kurtzke EDSS rank stability increases 4 years after the onset of multiple sclerosis: results from the MSBase Registry
}

Kee, F., \& Al, E. (2012). The Kurtzke EDSS rank stability increases 4 years after the onset of multiple sclerosis: results from the MSBase Registry. JOURNAL OF NEUROLOGY NEUROSURGERY AND PSYCHIATRY, 83(3), 305-310. https://doi.org/10.1136/jnnp-2011-301051

Published in:

JOURNAL OF NEUROLOGY NEUROSURGERY AND PSYCHIATRY

Queen's University Belfast - Research Portal:

Link to publication record in Queen's University Belfast Research Portal

\section{General rights}

Copyright for the publications made accessible via the Queen's University Belfast Research Portal is retained by the author(s) and / or other copyright owners and it is a condition of accessing these publications that users recognise and abide by the legal requirements associated with these rights.

Take down policy

The Research Portal is Queen's institutional repository that provides access to Queen's research output. Every effort has been made to ensure that content in the Research Portal does not infringe any person's rights, or applicable UK laws. If you discover content in the Research Portal that you believe breaches copyright or violates any law, please contact openaccess@qub.ac.uk. 


\title{
The Kurtzke EDSS rank stability increases 4 years after the onset of multiple sclerosis: results from the MSBase Registry
}

\author{
Stella Hughes, ${ }^{1,2,3}$ Timothy Spelman, ${ }^{1}$ Maria Trojano, ${ }^{4}$ Alessandra Lugaresi, ${ }^{5}$ \\ Guillermo Izquierdo, ${ }^{6}$ Francois Grand'Maison, ${ }^{7}$ Pierre Duquette, ${ }^{8}$ Marc Girard, ${ }^{8}$ \\ Pierre Grammond ${ }^{9}$ Celia Oreja-Guevara, ${ }^{10}$ Raymond Hupperts, ${ }^{11}$ Cavit Boz, ${ }^{12}$ \\ Roberto Bergamaschi, ${ }^{13}$ Giorgio Giuliani, ${ }^{14}$ Maria Edite Rio, ${ }^{15}$ \\ Jeannette Lechner-Scott, ${ }^{16}$ Vincent van Pesch, ${ }^{17}$ Gerardo Iuliano, ${ }^{18}$ Marcela Fiol, ${ }^{19}$ \\ Freek Verheul, ${ }^{20}$ Michael Barnett, ${ }^{21}$ Mark Slee, ${ }^{22}$ Joseph Herbert, ${ }^{23}$ Ilya Kister, ${ }^{23}$ \\ Norbert Vella, ${ }^{24}$ Fraser Moore, ${ }^{25}$ Tatjana Petkovska-Boskova, ${ }_{1}^{26}$ Vahid Shaygannejad, ${ }_{1}^{27}$ \\ Vilija Jokubaitis, ${ }^{1}$ Gavin McDonnell, ${ }^{2}$ Stanley Hawkins, ${ }^{2,3}$ Frank Kee, ${ }^{3}$ Orla Gray, ${ }^{28}$ \\ Helmut Butzkueven, ${ }^{1,29,30}$ on behalf of the MSBase Study Group
}

For numbered affiliations see end of article.

\section{Correspondence to} Professor Helmut Butzkueven, MS Clinical and Research Unit, Department of Medicine, Royal Melbourne Hospital and University of Melbourne, Grattan St, Parkville, Victoria 3050, Australia; butz@unimelb.edu.au

To see the members of the MSBase Study group see end of article.

$\mathrm{OG}$ and $\mathrm{HB}$ contributed equally to this work.

Received 27 July 2011 Revised 2 November 2011 Accepted 21 November 2011 Published Online First 28 December 2011

\section{ABSTRACT}

Background The Expanded Disability Status Scale (EDSS) is widely used to rate multiple sclerosis (MS) disability, but lack of disease duration information limits utility in assessing severity. EDSS ranking at specific disease durations was used to devise the MS Severity Score, which is gaining popularity for predicting outcomes. As this requires validation in longitudinal cohorts, we aimed to assess the utility of EDSS ranking as a predictor of 5-year outcome in the MSBase Registry.

Methods Rank stability of EDSS over time was examined in the MSBase Registry, a large multicentre MS cohort. Scores were ranked for 5-year intervals, and correlation of rank across intervals was assessed using Spearman's rank correlation. EDSS progression outcomes at 10 years were disaggregated by 5 -year EDSS scores.

Results Correlation coefficients for EDSS rank over 5-year intervals increased with MS duration: years $1-6=0.55$, years $4-9=0.74$, years $7-12=0.80$ and years $10-15=0.83$. EDSS progression risk at 10 years after onset was highly dependent on EDSS at 5 years; one-point progression risk was greater for EDSS score of $>2$ than $\leq 2$. Two-point progression was uncommon for EDSS score of $<2$ and more common at EDSS score of 4.

Conclusions EDSS rank stability increases with disease duration, probably due to reduced relapses and less random variation in later disease. After 4 years duration, EDSS rank was highly predictive of EDSS rank 5 years later. Risk of progression by 10 years was highly dependent on EDSS score at 5 years duration. We confirm the utility of EDSS ranking to predict 5-year outcome in individuals 4 years after disease onset.

\section{INTRODUCTION}

Multiple sclerosis (MS) is the most common cause of neurological disability in young adults in the developed world. However, there is marked variability in the degree of disability in MS among people who have the same disease duration. The most widely used validated measure of disability is the Kurtzke Expanded Disability Status Scale (EDSS). ${ }^{1}$ This is a non-linear scale with 19 numbered half-steps ranging from 0 , indicating no disability, to a score of 10 , denoting death due to MS. An EDSS score between 4.0 and 9.5 is determined largely by the degree to which an individual's ambulation is impaired. A score from 0 to 3.5 is applied to fully ambulatory patients and calculated by scoring maximal impairment in each of the Kurtzke Functional Systems, consisting of pyramidal, cerebellar, brainstem, sensory, bowel/bladder, cerebral/mental, visual and 'other' categories.

The EDSS is commonly used in both clinical and research settings to delineate an individual's disease progression. However, in order to assess the disease severity, some measure of disease duration should ideally be incorporated into this score. The global Multiple Sclerosis Severity Score (MSSS), proposed by Roxburgh and colleagues, has provided researchers with a tool to quantify the degree of neurological disability for a given duration of MS. The MSSS was devised using a database containing 9892 European and Australian MS cases from 11 countries. ${ }^{2}$ For most patients, a single EDSS score was recorded. EDSS scores were stratified according to the time since the onset of MS and ranked for years $1-30$. The MSSS simply represents this rank of EDSS for a cohort of a given disease duration expressed as a decile.

In order to validate the predictive value of the MSSS, the authors assessed the stability of the MSSS over time in two French longitudinal cohorts in which serial EDSS scores had been recorded. A mean change of zero was observed in the MSSS for each group, despite significant variation in an individual's scores at different time points. ${ }^{2}$ They 
concluded that the MSSS could be used to measure and compare disease severity in groups of MS patients but that it had not yet been shown to be suitable for tracking an individual's progress over time. Consequently, the MSSS has been used in a number of research studies, ${ }^{3-9}$ including two genome-wide association scans of MS severity ${ }^{8}$ and has also recently been used to compare the disease severity among white and African American US patients ${ }^{10}$ and to investigate the changing disease severity in temporally separated cohorts in the New York State Multiple Sclerosis Consortium Database. ${ }^{11}$ In light of its increasing popularity, we decided to assess the performance of EDSS ranks as a predictor of 5-year outcome in the MSBase cohort, using cohorts with different baseline disease durations, all assessed prospectively for 5 years. We also aimed to disaggregate the probability of disability progression by EDSS scores at a disease duration of 5 years, in order to provide neurologists with a clinically meaningful risk stratification for the subsequent 5 years.

\section{METHODS}

\section{MSBase Registry}

The MSBase Registry prospectively collects outcomes data in MS from participating neurology centres worldwide using an internet-based system (https://www.msbase.org). Each centre records patient details in an offline local electronic database using iMed@ software and intermittently uploads anonymised datasets to the MSBase server. A minimum required dataset must be fulfilled before a record is deemed complete and eligible for inclusion. Data include the date of onset of MS, diagnostic criteria met and results of investigations such as MRI, evoked potentials and cerebrospinal fluid examination. During a patient's routine clinic visit, the clinician adds information on relapses and treatments and records an EDSS score at least annually. Informed consent is obtained from all patients for inclusion of their anonymised data in MSBase, and each centre has obtained Human Research Ethics Committee approval or exemption. Data were extracted for this study on 17 May 2010. All participating neurologists have obtained Neurostatus certification for EDSS competency (http://www.neurostatus.net).

\section{Inclusion and exclusion criteria}

All analysed cases met Poser criteria for definite $\mathrm{MS}^{12}$ or McDonald criteria for $\mathrm{MS}^{13}$ and were within 15 years of onset of MS. Disease onset was defined as the date of first symptom attributable to MS. EDSS scores which were known to be recorded at a clinic visit during a relapse were excluded. Cases who had at least two recorded EDSS scores 5 years apart were included. For each cohort, an EDSS score was only included if there was also a score recorded for that patient 5 years later. Cases did not necessarily have an EDSS score recorded in more than one time interval. Cases excluded from the analysis were those who had only a single EDSS score recorded (2545 patients) and those who had no EDSS scores recorded (697 patients). There were also 6348 patients excluded for whom at least two EDSS scores were recorded but whose EDSS scores were less than 5 years apart. Following these exclusions, a total of 13676 EDSS scores from 4219 patients were analysed. The number of EDSS scores included for each time interval is shown in table 2.

\section{Cohort}

In May 2010, the MSBase Registry had 14062 cases enrolled from 67 centres in 27 countries. Data extracted for this study were taken from 42 centres in 19 countries with 91730 complete
EDSS calculations from 13809 patients. Centres of origin were European in $65.3 \%$ of cases, $21.3 \%$ were from North America, $5.5 \%$ from Australia, 5.2\% were from Central and South America and $2.9 \%$ from Near-East Asia. The number of patients by country is shown in table 1. The female to male ratio was 2.3:1. Relapsing remitting MS comprised $74.3 \%$ of cases, $16.7 \%$ had secondary progressive or progressive relapsing MS, $4.5 \%$ had primary progressive $\mathrm{MS}$ and $\mathrm{MS}$ type was unknown in $4.5 \%$.

\section{Statistical analysis}

For each eligible patient, an EDSS score was determined for each year from the onset of MS up to 15 years. A median EDSS score was calculated over a 2-year period if more than one score was recorded within this time. For example, a 'year 4 score' was the median of EDSS scores recorded between 3 and 5 years since the onset of MS. Year 0 scores were omitted from analysis as EDSS scores at onset of MS have previously been shown to have poor correlation with scores later in the disease course. ${ }^{2}$

Patients who had at least two EDSS scores recorded 5 years apart were divided into subsets according to the time intervals in which these scores fell. Time intervals were as follows: 1-6, 2-7, 3-8, 4-9, 5-10, 6-11, 7-12, 8-13, 9-14 and $10-15$ years. EDSS scores were ranked for both the year at the beginning and the year at the end of the interval. The rank of EDSS for patients across each 5-year time interval was charted with jittered scatterplots. Spearman's rank correlation (with 95\% CIs) was used to assess the correlation of EDSS rank at the beginning and end of the 5-year time intervals. The change in EDSS score, as a function of baseline score for the 5-10 year subgroup, was analysed further, and rates of progression were compared between groups using $\chi^{2}$ test. All statistical analyses were performed using Stata ${ }^{\circledR}$ software, V.11

\section{RESULTS}

\section{Disability and treatment}

The median age at onset of MS in this cohort was 30.4 years (IOR 24.1-38.3 years), and median duration of disease was 10.9 years (IOR 7.9-14.4 years). Table 2 shows the median EDSS at the beginning of each time interval. Disease progression has been compared in this study with the original cohort used

Table 1 Country of origin for patients included in the analysis of this study

\begin{tabular}{lc}
\hline Country & Patients, n (\%) \\
\hline Italy & $1452(34.4)$ \\
Canada & $898(21.3)$ \\
Spain & $503(11.9)$ \\
Netherlands & $442(10.5)$ \\
Australia & $233(5.5)$ \\
Argentina & $143(3.4)$ \\
Portugal & $129(3.1)$ \\
Denmark & $108(2.6)$ \\
Belgium & $87(2.1)$ \\
Turkey & $70(1.7)$ \\
Cuba & $68(1.6)$ \\
Israel & $52(1.2)$ \\
Malta & $20(0.5)$ \\
Brazil & $8(0.2)$ \\
France & $4(0.1)$ \\
Macedonia & $2(0.05)$ \\
Total patients & 4219 \\
\hline
\end{tabular}


Table 2 Number of EDSS scores examined, median EDSS scores at start of interval and correlation coefficients for rank of EDSS at start and end of intervals

\begin{tabular}{llll}
\hline $\begin{array}{l}\text { 5-year time } \\
\text { interval } \\
\text { (years) }\end{array}$ & $\begin{array}{l}\text { No. of EDSS } \\
\text { scores analysed }\end{array}$ & $\begin{array}{l}\text { Median EDSS } \\
\text { score (IOR) } \\
\text { at start of } \\
\text { interval }\end{array}$ & $\begin{array}{l}\text { Spearman's rank } \\
\text { correlation } \\
\text { coefficients (95\% CI) } \\
\text { for EDSS rank across } \\
\text { interval }\end{array}$ \\
\hline $1-6$ & 1664 & $1.75(1.0-2.5)$ & $0.55(0.52$ to 0.59) \\
$2-7$ & 1601 & $2.0(1.0-2.5)$ & $0.63(0.60$ to 0.66$)$ \\
$3-8$ & 1567 & $2.0(1.0-3.0)$ & $0.63(0.61$ to 0.66$)$ \\
$4-9$ & 1507 & $2.0(1.25-3.5)$ & $0.74(0.72$ to 0.76$)$ \\
$5-10$ & 1426 & $2.0(1.5-3.5)$ & $0.77(0.75$ to 0.79$)$ \\
$6-11$ & 1391 & $2.0(1.5-4.0)$ & $0.77(0.74$ to 0.79$)$ \\
$7-12$ & 1264 & $2.5(1.5-4.0)$ & $0.80(0.77$ to 0.81$)$ \\
$8-13$ & 1199 & $2.5(1.5-4.0)$ & $0.79(0.77$ to 0.81$)$ \\
$9-14$ & 1065 & $2.5(1.5-4.5)$ & $0.83(0.81$ to 0.84$)$ \\
$10-15$ & 992 & $2.75(1.5-4.75)$ & $0.83(0.81$ to 0.85$)$ \\
\hline Cl, confidence intervals; EDSS, Expanded Disability Status Scale; IOR, interquartile \\
range.
\end{tabular}

by Roxburgh to develop the MSSS, as shown in table 3. It appears that our cohort has less severe disease than that reported in a similar sized dataset by Roxburgh and colleagues ${ }^{2}$ in 2005, which was collected as part of the GAMES genetics study in the late 1990s. One possible explanation for this discrepancy could be increased exposure to disease-modifying treatments. In our cohort, $81.3 \%$ of patients had been exposed at some time to an immunomodulatory drug for MS (excluding corticosteroids), with a median duration of exposure of 2.3 years (IOR 1.0-5.1 years). In 78.4\% of cases, there was exposure to interferon or glatiramer acetate, with a median duration of treatment 2.6 years (IOR 1.0-5.4 years). Exposure to other immunomodulatory drugs, including natalizumab, azathioprine, cyclophosphamide, methotrexate and mitoxantrone, was observed in $16.4 \%$ of cases for a median duration of 1.7 years (IOR 0.7-2.7 years).

\section{Rank stability}

Spearman's rank correlation coefficients were calculated for each of the time intervals analysed to determine the stability of the EDSS rank over time. Results revealed that EDSS rank stability increases with disease duration as correlation coefficients increased from 0.55 for years $1-6$ to 0.74 for years $4-9$, 0.77 for years $5-10,0.80$ for years $7-12$ to 0.83 for years $10-15$.

Table 3 Comparison of patients reaching EDSS milestone scores in the current study (for those whose scores were analysed for the disease durations below) with the cohort used to devise the MSSS $^{2}$

\begin{tabular}{llcc}
\hline $\begin{array}{l}\text { Disease } \\
\text { duration } \\
\text { (years) }\end{array}$ & $\begin{array}{l}\text { EDSS score greater } \\
\text { than or equal to }\end{array}$ & $\begin{array}{l}\text { Patients in this } \\
\text { study, } \mathbf{n}(\%)\end{array}$ & $\begin{array}{l}\text { Patients in original } \\
\text { MSSS cohort (\%) }\end{array}$ \\
\hline 5 & 3 & $530(37.2)$ & 48 \\
& 6 & $94(6.6)$ & 14 \\
& 8 & $9(0.6)$ & 4 \\
10 & 3 & $495(49.9)$ & 67 \\
& 6 & $168(16.9)$ & 30 \\
& 8 & $14(1.4)$ & 5 \\
15 & 3 & $607(61.2)$ & 75 \\
& 6 & $273(27.5)$ & 38 \\
& 8 & $33(3.3)$ & 11 \\
\hline
\end{tabular}

EDSS, Expanded Disability Status Scale; MSSS, Multiple Sclerosis Severity Score.
Scatterplots for four of the time intervals examined are displayed in figure 1, showing rank of EDSS for two time points 5 years apart with jittering to visually represent tied values. The additional axes show the EDSS scores at the beginning and end of each of the intervals shown. On visual inspection of the graphs, cases increasingly lie around the leading diagonal as disease duration increases. The correlation coefficients for the remaining intervals are shown in table 2 . These results suggest that the within-cohort rank of a person's EDSS is increasingly consistent or 'stable' over 5 years, with strong correlation observed from 4 years after the onset of MS.

As expected, the majority of cases in the cohorts with shorter disease durations have EDSS scores in the lower ranges, as is evident on inspection of figure 1. Although constituting a small proportion of patients in this study, those with higher EDSS scores earlier in their disease course are more likely to maintain a high EDSS ranking over time. We therefore examined the rank stability further in those with EDSS scores in the lower range, where variability over time is more likely to occur. Spearman's rank correlation was used to assess correlation of EDSS rank over 5 years for cases who had an EDSS score between 0 and 3.5 at the beginning of the 5-year time intervals. Again, increasing correlation was observed as disease duration increased with coefficients of 0.46 for years $1-6,0.60$ for years $4-9,0.61$ for years $7-12$ and 0.62 for years $10-15$.

\section{Change in EDSS scores}

As EDSS ranks are difficult to interpret in clinical practice, we explored the predictive risks of disability progression from 5-year EDSS scores for the subsequent 5 years. The change in EDSS scores over time was explored further for the 5-10-year disease duration interval, due to its utility in previous studies examining the predictive value of early disease course in MS outcomes. $^{2} 1415$ In order to explore the probability of EDSS worsening over the subsequent 5 years as a function of EDSS at 5 years of disease duration, we tabulated the percentage of MS patients with an increase in the EDSS score of either 1 or 2 points over the $5-10$-year interval, disaggregated by EDSS score at 5 years duration. The proportion of patients with one- and two-point progressions was dependent on EDSS scores at 5 years. The probability of a one-point progression for patients with 5 -year EDSS scores of 1, 1.5 or 2 was around $30 \%$ but rose sharply to over $50 \%$ for patients with a 5 -year EDSS score of 2.5 or greater $(p<0.001)$ (see table 4$)$. The probability of a two-point progression for patients with 5 -year EDSS scores of 1 or 1.5 was only around $10 \%$, for 5 -year scores between 2 and 3.5, it was around $20 \%$, but for patients with a 5 -year EDSS score of 4 , it rose sharply to almost $40 \%$ (see table 4$)(p<0.001)$.

\section{DISCUSSION}

In this study, we aimed to validate the longitudinal stability of EDSS ranking in clinical practice using the MSBase Registry, a large longitudinal dataset of MS patients. We observed strong correlation between a patient's rank of EDSS score at one time point and the rank of their EDSS score 5 years later, in cohorts with disease duration of 4 years and longer. Our results suggest the utility of EDSS ranking as a tool to assess disease severity in individual patients of at least 4 years of disease duration. This type of ranking tool could ultimately provide a basis on which to test outcomes of different treatment choices, allowing the potential validation of proposed treatment algorithms.

Although 5-year prospective EDSS ranks stabilised after a disease duration of 4 years, examination of progression 

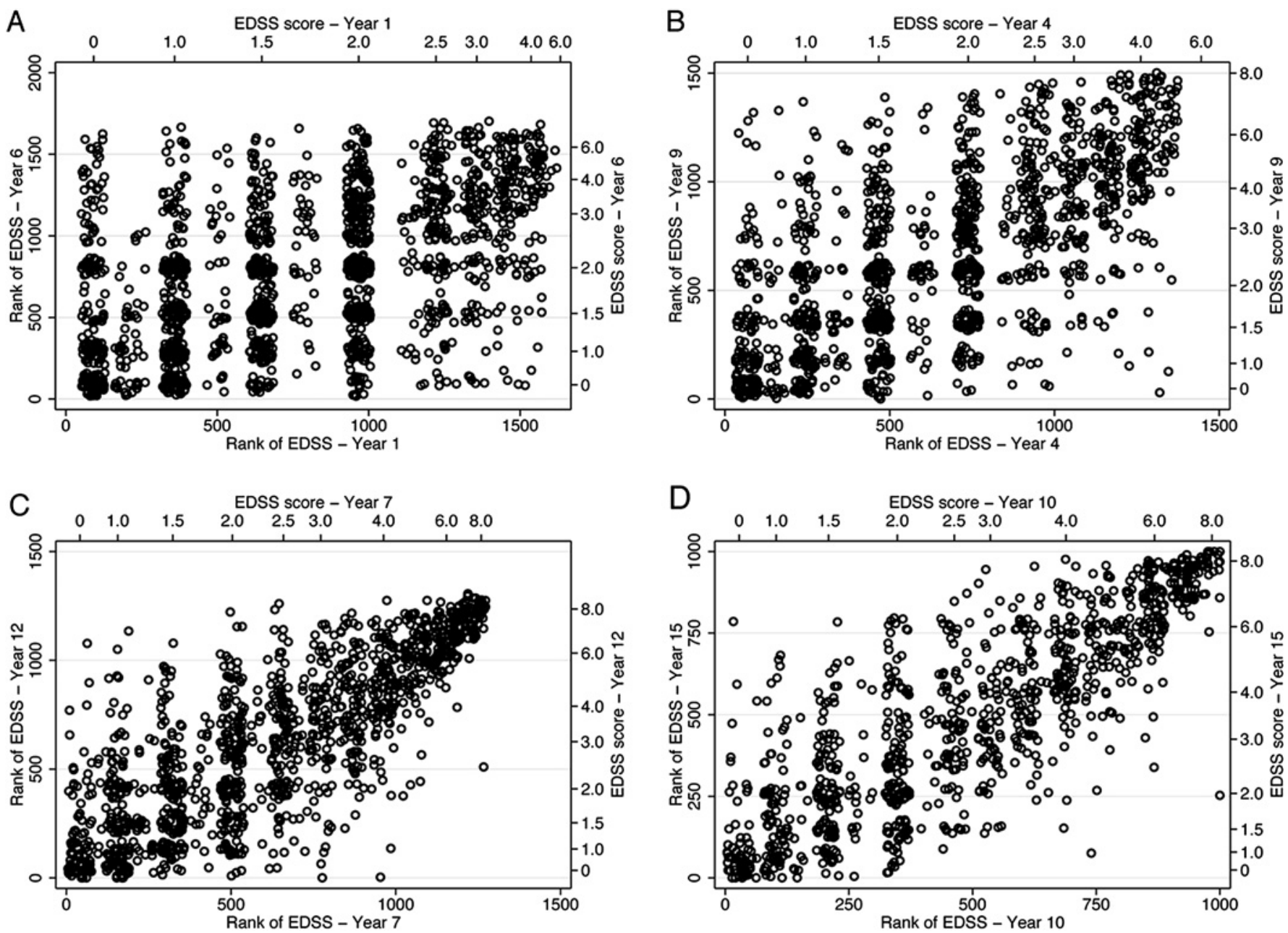

Figure 1 (A-D) Rank of Expanded Disability Status Scale (EDSS) for cases analysed for the following 5-year time intervals: (A) years 1-6, (B) years $4-9,(C)$ years $7-12$ and (D) years $10-15$. The additional axes show EDSS scores at the start and end of the interval for each cohort.

probabilities from different EDSS scores in the year 5-10 cohort may suggest critical EDSS values determining the risk of subsequent one or two-point EDSS increases over the next 5 years. The ability to identify patients with high progression rates at 5 years of disease duration would be of use clinically and in future observational studies to examine the effect of treatment escalation in this population. From this exploratory analysis, we propose that cases with a 5 -year EDSS score of $0-1.5$ are at low risk, 2.0-3.5 at intermediate risk and a score of 4.0 or 4.5 are at high risk of two-point (ie, severe) EDSS progression by 10 years after disease onset.

Our findings add to those of previous observational studies, in which early disease course was found to predict later outcomes, validating this concept in a very large clinical practice cohort. Originally, Kurtzke investigated factors that predicted disability at later stages of disease in a cohort of 527 patients with MS, ${ }^{14}$ using the Disability Status Scale (DSS), which he later refined as the EDSS. ${ }^{1}$ The best predictor of DSS at disease durations of 10 and 15 years was found to be the DSS score at 5 years after onset, with a correlation coefficient exceeding 0.7 . The scores for both the pyramidal and cerebellar components of the DSS at 5 years were also predictive of later disability, although less so than the overall DSS score at 5 years. In the London Ontario natural history studies, it was also observed that the DSS at both 2 and 5 years was predictive of disability later in the disease course. ${ }^{15}$ Using the MSBase Registry, further study will include analysis of lead components of the EDSS, or Kurtzke Functional System scores, to determine which of these contribute to the stability of EDSS rank over time.

Table 4 Increase in EDSS scores for cohort of patients examined across the 5-10-year interval

\begin{tabular}{lll}
\hline $\begin{array}{l}\text { EDSS score at } \\
\text { years after the } \\
\text { onset of } \text { MS }^{*}\end{array}$ & $\begin{array}{l}\text { EDSS score } \geq 1.0-p o i n t \\
\text { increase at 10 years, } \\
\mathbf{n}(\%)\end{array}$ & $\begin{array}{l}\text { EDSS score } \mathbf{2 . 0} \text {-point } \\
\text { increase at 10 years, } \\
\mathbf{n}(\%)\end{array}$ \\
\hline 0 & $63(54.3)$ & $19(16.4)$ \\
1.0 & $66(35.3)$ & $18(9.6)$ \\
1.5 & $65(27.6)$ & $22(9.1)$ \\
2.0 & $80(32.7)$ & $44(18.0)$ \\
2.5 & $63(54.3)$ & $24(20.7)$ \\
3.0 & $54(46.9)$ & $27(23.5)$ \\
3.5 & $61(52.2)$ & $27(23.1)$ \\
4.0 & $56(54.8)$ & $40(39.2)$ \\
4.5 & $24(64.9)$ & $13(35.1)$ \\
5.0 & $25(73.5)$ & $9(26.5)$ \\
5.5 & $15(48.4)$ & $3(9.7)$ \\
6.0 & $18(42.9)$ & $3(7.1)$ \\
$\geq 6.5$ & $16(31.4)$ & $1(2.0)$ \\
\hline
\end{tabular}

*'EDSS score at 5 years' represents the median of all scores recorded for an individual between 4 and 6 years after the onset of MS.

EDSS, Expanded Disability Status Scale. 
Lastly, the MSSS was found to be stable over time when initially validated by Roxburgh et $a l^{2}$ using a subset of 3605 patients from the Lyons and Rennes cohorts. Strong correlation in disability ranking was observed in individuals from 3 years after the onset of MS at time points 5, 10 and 15 years later. However, there was evidence that the MSSS fluctuated for patients over time and so caution was advised in interpreting the MSSS for individuals rather than groups.

Our cohort has similar characteristics to the combined groups used to devise the MSSS, with respect to the age at onset and disease duration. ${ }^{2}$ Centres from Europe, North, Central and South America, Australia and Near-East Asia contributed patients to the present study, in which $34.9 \%$ of the cohort were from non-European centres. This encompasses a more geographically diverse sample than Roxburgh's cohort, in which 99\% of cases were from Europe. The cohorts also differ drastically with respect to treatment exposure. Roxburgh's original cohort was a largely untreated group (27\% treated), whereas $81.3 \%$ of patients in our cohort had been treated with an immunomodulatory drug for MS, other than corticosteroids.

The difference in rates of treatment exposure may account for the smaller proportion of patients in this cohort reaching disability milestones compared with Roxburgh's cohort, as shown in table 3 . There is supportive evidence that diseasemodifying treatments can delay or attenuate disability in MS, as observed in a number of studies involving interferon- $\beta$ and glatiramer acetate. ${ }^{16-21}$ A recent study using the New York State MS Consortium compared the distribution of the MSSS for patients enrolled between 1996 and 2007. ${ }^{11}$ It was observed that the more recent enrollees had lower MSSSs than earlier enrollees, and this appeared to be independent of age, gender, ethnicity and time of diagnosis. The authors hypothesised that this apparent reduction in disease severity may be due to long-term efficacy of disease-modifying treatment, given that exposure to diseasemodifying treatments rose from $51 \%$ to $71 \%$ over the course of the time period examined. The effect of treatment on rank stability of the EDSS will be explored further in a future study using the MSBase Registry.

This study is of course limited by the drawbacks of the EDSS itself, which includes the non-linearity of the scale and potential for variability in its grading. However, this is the gold standard disability grading tool in MS, and it is therefore widely used. Inter-rater variability on assessment of EDSS in patients with MS has been observed. ${ }^{22}$ This effect is most important at the lower end of the scale where symptoms and subtle signs can determine scores giving rise to subjective rating by patients and clinicians. We anticipated fluctuations and 'regression to the mean' effects for EDSS scores in our cohort and attempted to minimise this by using a median EDSS score, taken over a 2-year interval to define the disease-duration-specific EDSS. We also considered the possibility of 'apparent' rank stability, as those with higher EDSS ranks early in the disease course may maintain a high rank due to severe irreversible disability. However, on assessment of those with EDSS scores below 4.0 at the beginning of 5-year intervals, correlation of EDSS rank over 5-year intervals also became strong after 4 years of disease duration.

\section{CONCLUSIONS}

This study has confirmed increasing stability of EDSS ranks over 5 -year intervals in individuals from a disease duration of 4 years using a large global database of MS patients in the MSBase Registry. It also suggests that certain EDSS score cut-off points for risk of 5-year EDSS progression could be defined to identify cohorts at high risk of progression in both clinical and research settings. Although EDSS ranking was originally used in the MSSS to allow comparison of severity between groups, we propose that EDSS ranks at specific disease durations can be used to assess and monitor disease severity in individuals.

\section{Author affiliations}

${ }^{1}$ Department of Neurology, Royal Melbourne Hospital, Victoria, Australia

${ }^{2}$ Royal Victoria Hospital, Belfast, UK

${ }^{3}$ UKCRC Centre of Excellence for Public Health Research, Queen's University Belfast,

Belfast, UK

${ }^{4}$ University of Bari, Bari, Italy

${ }^{5} \mathrm{MS}$ Center, Department of Neuroscience and Imaging, University of 'G. d'Annunzio', Chieti, Italy

${ }^{6}$ Hospital Universitario, Sevilla, Spain

${ }^{7}$ Neuro Rive-Sud, Quebec, Canada

${ }^{8}$ Hopital Notre Dame, Montreal, Canada

${ }^{9}$ Hotel-Dieu de Levis, Quebec, Canada

${ }^{10}$ Hospital Universitario La Paz, IdiPAZ, Madrid, Spain

${ }^{11}$ Maaslandziekenhuis, Sittard, The Netherlands

${ }^{12}$ Karadeniz Technical University, Trabzon, Turkey

${ }^{13}$ Neurological Institute IRCCS Mondino, Pavia, Italy

${ }^{14}$ Ospedale di Macerata, Macerata, Italy

${ }^{15}$ Hospital S. Joao, Porto, Portugal

${ }^{16}$ John Hunter Hospital, New South Wales, Australia

${ }^{17}$ Cliniques Universitaires Saint Luc, Brussels, Belgium

${ }^{18}$ Ospedali Riuniti di Salerno, Salerno, Italy

${ }^{19} \mathrm{FLENI}$, Buenos Aires, Argentina

${ }^{20}$ Groen Hart Ziekenhuis, Gouda, The Netherlands

${ }^{21}$ Brain and Mind Research Institute, New South Wales, Australia

${ }^{22}$ Flinders Medical Centre, South Australia, Australia

${ }^{23}$ New York University Hospital for Joint Diseases, New York, USA

${ }^{24}$ Mater Dei Hospital, Msida, Malta

${ }^{25}$ Jewish General Hospital, Montreal, Canada

${ }^{26}$ Clinic of Neurology Clinical Center, Skopje, Macedonia

${ }^{27} \mathrm{Al}$-Zahra Hospital, Isfahan University of Medical Sciences, Isfahan, Iran

${ }^{28}$ Craigavon Area Hospital, Portadown, UK

${ }^{29}$ Department of Medicine, The University of Melbourne, Victoria, Australia

${ }^{30}$ Department of Neurology, Box Hill Hospital, Monash University, Victoria, Australia

Collaborators From University Hospital Nijmegen, The Netherlands, Dr Cees Zwanikken; From the University of Bari, Italy, Dr Damiano Paolicelli, Dr Guglielmo Lucchese and Dr Pietro laffaldano; From University of 'G. d'Annunzio', Chieti, Italy,

Dr Giovanna De Luca, Dr Valeria Di Tommaso, Dr Daniela Travaglini, Dr Erika Pietrolongo, Dr Maria di loia and Dr Deborah Farina; From the Royal Melbourne Hospital, Australia, Dr Mark Marriott, Dr Trevor Kilpatrick, Dr John King, Dr Anneke Van der Walt, Ms Michelle Rutherford and Mrs Mary Tanner; From

Kommunehospitalet, Aarhus C, Denmark, Dr Thor Petersen; From Ospedale di Macerata, Macerata, Italy, Dr Elisabetta Cartechini and Eugenio Pucci; From John Hunter Hospital, New South Wales, Australia, Dr David William and Dr Lisa Dark; From FLENI, Buenos Aires, Argentina, Dr Jorge Correale and Dr Celica Ysrraelit; From Francicus Ziekenhuis, The Netherlands, Ms Leontien Den Braber-Moerland; From Hospital Italiano, Buenos Aires, Argentina, Dr Edgardo Cristiano; From Multiple Sclerosis Centre Kamillus-Klinik, Asbach, Germany, Dr Dieter Poehlau; From INEBA, Buenos Aires, Argentina, Dr Maria Laura Saladino; From Hospital Fernandez, Buenos Aires, Argentina, Dr Norma Deri, Dr Gonzalo Jaacks, Dr Maria Fernanda Páez, Dr Daniel Muñoz and Dr Alfredo Laffue; From Instituta de Neurologica de Curibita, Curibita, Brazil, Dr Walter Oleschko Arruda; From Assaf Harofeh Medical Center, Beer-Yaakov, Israel, Dr Shlomo Flechter; From St Vincents Hospital, Victoria, Australia, Dr Mark

Paine; From Centro Internacional de Restauracion Neurologica, Havana, Cuba, Dr Jose Antonio Cabrera-Gomez; From Consultorio Privado, Buenos Aires, Argentina, Dr Aldo Savino; From Mater Dei Hospital, Msida, Malta, Dr Malcolm Vella; From Geelong Hospital, Victoria, Australia, Dr Cameron Shaw; From Hospital de Especialidades. Centro Medico Nacional Siglo XXI, Mexico, Dr Eli Skromne; From HIGA Gral, San Martin La Plata, Argentina, Dr Vetere Santiago; From Instituto de Neurociencias Cordoba, Argentina, Dr Elisabeth Bacile.

Funding This study was funded by the MSBase Foundation, a not-for-profit organisation. The MSBase Foundation receives financial support from Merck Serono, Biogen Idec, Novartis Pharma, Bayer Schering and Sanofi Aventis.

Correction notice This article has been corrected since it was published Online First. Some of the author affiliations were incorrect and these have now been rectified.

Competing interests SHu has received unrestricted educational grants from Bayer Schering Australia, Biogen Idec, Merck Serono and Sanofi Aventis. MT received honoraria for consultancy and/or speaking from Biogen Idec, Sanofi-Aventis, Merck Serono and Bayer Schering and research grants from Merck Serono, Biogen Idec and Novartis Pharma. AL is a Biogen Dompe, Merck Serono and Bayer Schering advisory board member. She receives travel grants and honoraria from Bayer Schering, Biogen 
Dompe, Merck Serono, Novartis, Sanofi Aventis and Teva and research grants from Bayer Schering, Biogen Dompe, Merck Serono, Novartis and Sanofi Aventis. She is a member of the steering committee of a trial sponsored by Merck Serono and is the Italian coordinator of a Biogen-Dompé study. She has also received travel and research grants from the Associazione Italiana Sclerosi Multipla and is a consultant of 'Fondazione Cesare Serono'. Glz has received honoraria for consultation from Biogen Idec, Merck Serono, Teva, Bayer, Novartis and Sanofi Aventis. FG is a Novartis advisory board member and receives Speakers Bureau from Teva and research grants from Genzyme, Novartis, Biogenldec, Teva, ONO, UBC and EMD Serono. PD reports participating in advisory boards for TEVA, EMD Serono, Biogen Idec, Novartis and Bayer Schering. He also receives research grants from Biogen Idec, CIHR and the MS Society of Canada. MG reports participating in advisory boards for Teva Neuroscience and Biogen Idec. He has received travel grants from Biogen Idec and EMD Serono as well as honoraria for speaking engagements from Teva Neurosciences, Biogen Idec, EMD Serono and Novartis Pharma. PG has received research grants from Sanofi-Avantis and Biogen-Idec. PG has also received honoraria for advisory councils and teaching programs with Novartis Pharma, Teva Neuroscience, EMD Serono, Biogen Idec and Bayer. CO-G has received honoraria as consultant in scientific advisory boards by Biogen-Idec, Bayer-Schering, Merck-Serono, Teva and Novartis and has also participated in clinical trials and other research projects promoted by Biogen-Idec, GSK, Teva and Novartis. RH has received honoraria for consultancy for Biogen Idec, reports participating in an advisory board for Merck Serono and has received grants from Biogen Idec and Merck Serono. RB has received research grants from Bayer-Schering, Biogen Dompè, Novartis, Sanofi Aventis and Merck Serono; honoraria for speaking from Bayer-Schering, Sanofi Aventis and Merck Serono; grants to cover travel expenses from Bayer-Schering, Biogen Dompè, Sanofi Aventis, Merck Serono and Novartis. MER has received payment for lectures from Serono Symposia International. JL-S institution receives non-directed funding as well as honoraria for presentations and membership on advisory boards from Sanofi Aventis, Biogen Idec, Bayer Health Care, Merck Serono and Novartis Australia. VvP serves on an advisory board for Biogen Idec. He has received travel grants from Biogen Idec, Bayer Schering, Sanofi Aventis, Merck Serono and Novartis Pharma and speaking honoraria from Biogen Idec. MF received conference travel support from Merck Serono. FV has received honoraria as a member of an advisory board for Merck Serono. MB has received research support and/or honoraria from Bayer Schering, Biogen Idec, Merck Serono, Novartis Pharma, Sanofi Aventis and Teva. MS reports participating in advisory boards for Sanofi Aventis, Merck Serono, Biogen Idec, Novartis Pharma and Bayer Schering. JH receives honoraria from Teva, Bayer, Merck Serono and Biogen Idec. IK has received grants from the National MS Society and Bayer. NV receives honoraria from Novartis Pharma and conference travel support from Biogen Idec, Eisai, GSK, Novartis and Bayer Schering. FM has participated in MS clinical trials sponsored by EMD Serono and Bayer and has received honorarium from Teva and Bayer for consultancy, EMD Serono for organisation of a teaching course and Serono for speaking. He has also received conference support from Serono, Teva and Biogen. SHa has received an unrestricted educational grant and travel grants from Merck Serono. OG has received unrestricted educational grants from Merck Serono and Biogen Idec. HB has served on scientific advisory boards for Biogen Idec, Novartis and Sanofi-Aventis and has received conference travel support from Novartis, Biogen Idec and Sanofi Aventis. He serves on steering committees for trials conducted by Merck Serono, Biogen Idec and Novartis. HB has received research support from Merck Serono, Novartis and Biogen Idec in his capacity as honorary chair of the MSBase Foundation. He is on the editorial board of Multiple Sclerosis International. He is the recipient of a National Health and Medical Research Council (NHMRC) Career Development Award (628856), NHMRC Project Grants (566513, 628799, 1009757), NHMRC Centre of Excellence Award (1001216), an Australian Research Council Linkage Grant (LP110100473) RG and a National MS Society (USA) Project Grant (RG3850A3/1). TS, CB, GG, Glu, TP-B, VS, VJ, GM and FK report no disclosures.

Ethics approval Relevant ethics approvals or waivers were obtained at each participating site.

Contributors SHu aided in study design, interpretation of the data and drafted and revised the manuscript. TS aided in study design, performed the statistical analyses and interpretation of the data as well as drafting and revising the manuscript. MT, AL, Glz, FG, PD, MG, PG, CO-G, RH, CB, RB, GG, MER, JL-S, VvP, Glu, MF, FV, MB, MS, $\mathrm{JH}, \mathrm{IK}, \mathrm{NV}, \mathrm{FM}, \mathrm{TP}-\mathrm{B}, \mathrm{VS}, \mathrm{VJ}, \mathrm{GM}, \mathrm{SHa}$ and FK aided in revising the manuscript. OG designed and conceptualised the study, interpreted the data and drafted and revised the manuscript. HB designed and conceptualised the study, interpreted the data and drafted and revised the manuscript. He is guarantor of this work.

Provenance and peer review Not commissioned; externally peer reviewed.

\section{REFERENCES}

1. Kurtzke JF. Rating neurologic impairment in multiple sclerosis: an expanded disability status scale (EDSS). Neurology 1983;33:1444-52.

2. Roxburgh RH, Seaman SR, Masterman T, et al. Multiple Sclerosis Severity Score: using disability and disease duration to rate disease severity. Neurology 2005;64:1144-51.

3. Daumer M, Neuhaus A, Herbert J, et al. Prognosis of the individual course of disease: the elements of time, heterogeneity and precision. J Neurol Sci 2009;287 (Suppl 1):S50-5.

4. Karussis D, Teitelbaum D, Sicsic C, et al. Long-term treatment of multiple sclerosis with glatiramer acetate: natural history of the subtypes of anti-glatiramer acetate antibodies and their correlation with clinical efficacy. J Neuroimmunol 2010;220:125-30.

5. Van der Walt A, Stankovich J, Bahlo M, et al. Heterogeneity at the HLA-DRB1 allelic variation locus does not influence multiple sclerosis disease severity, brain atrophy or cognition. Mult Scler 2010;17:344-52.

6. Rejdak K, Eikelenboom MJ, Petzold A, et al. CSF nitric oxide metabolites are associated with activity and progression of multiple sclerosis. Neurology 2004;63:1439-45.

7. Brynedal B, Wojcik J, Esposito F, et al. MGAT5 alters the severity of multiple sclerosis. J Neuroimmunol 2010;220:120-4.

8. Baranzini SE, Wang J, Gibson RA, et al. Genome-wide association analysis of susceptibility and clinical phenotype in multiple sclerosis. Hum Mol Genet 2009;18:767-78

9. Briggs FB, Shao X, Goldstein BA, et al; International Multiple Sclerosis Genetics Consortium. Genome-wide association study of severity in multiple sclerosis. Genes Immun 2011;12:615-25.

10. Kister I, Chamot E, Bacon J, et al. Rapid disease course in African Americans with multiple sclerosis. Neurology 2010;75:217-23

11. Kister I, Chamot E, Bacon JH, et al. Trend for decreasing Multiple Sclerosis Severity Scores (MSSS) with increasing calendar year of enrollment into the New York State Multiple Sclerosis Consortium. Mult Scler 2011;17:725-33.

12. Poser CM, Paty DW, Scheinberg L, et al. New diagnostic criteria for multiple sclerosis: guidelines for research protocols. Ann Neurol 1983;13:227-31.

13. Polman CH, Reingold SC, Edan G, et al. Diagnostic criteria for multiple sclerosis: 2005 revisions to the "McDonald Criteria". Ann Neurol 2005:58:840-6.

14. Kurtzke JF, Beebe GW, Nagler B, et al. Studies on the natural history of multiple sclerosis-8. Early prognostic features of the later course of the illness. J Chronic Dis 1977; 30:819-30

15. Weinshenker BG, Rice GP, Noseworthy JH, et al. The natural history of multiple sclerosis: a geographically based study. 3. Multivariate analysis of predictive factors and models of outcome. Brain 1991;114:1045-56.

16. Ebers GC, Traboulsee A, Li D, et al. Analysis of clinical outcomes according to original treatment groups 16 years after the pivotal IFNB-1b trial. J Neurol Neurosurg Psychiatry 2010;81:907-12.

17. Ford C, Goodman AD, Johnson $K$, et al. Continuous long-term immunomodulatory therapy in relapsing multiple sclerosis: results from the 15-year analysis of the US prospective open-label study of glatiramer acetate. Mult Scler 2010;16: 342-50.

18. Kappos L, Traboulsee A, Constantinescu C, et al. Long-term subcutaneous interferon beta-1a therapy in patients with relapsing-remitting MS. Neurology 2006:67:944-53.

19. Trojano M, Pellegrini F, Fuiani A, et al. New natural history of interferon-beta-treated relapsing multiple sclerosis. Ann Neurol 2007;61:300-6.

20. Trojano M, Pellegrini F, Paolicelli D, et al. Real-life impact of early interferon beta therapy in relapsing multiple sclerosis. Ann Neurol 2009;66:513-20.

21. Veugelers PJ, Fisk JD, Brown MG, et al. Disease progression among multiple sclerosis patients before and during a disease-modifying drug program: a longitudinal population-based evaluation. Mult Scler 2009;15:1286-94.

22. Noseworthy JH, Vandervoort MK, Wong CJ, et al. Interrater variability with the Expanded Disability Status Scale (EDSS) and Functional Systems (FS) in a multiple sclerosis clinical trial. The Canadian Cooperation MS Study Group. Neurology 1990:40:971-5. 


\section{JNNP}

\section{The Kurtzke EDSS rank stability increases 4 years after the onset of multiple sclerosis: results from the MSBase Registry}

Stella Hughes, Timothy Spelman, Maria Trojano, et al.

J Neurol Neurosurg Psychiatry 2012 83: 305-310 originally published online December 28, 2011

doi: 10.1136/jnnp-2011-301051

Updated information and services can be found at:

http://jnnp.bmj.com/content/83/3/305.full.html

\section{These include:}

References This article cites 22 articles, 12 of which can be accessed free at: http://jnnp.bmj.com/content/83/3/305.full.html\#ref-list-1

Email alerting Receive free email alerts when new articles cite this article. Sign up in service the box at the top right corner of the online article.

\section{Topic Articles on similar topics can be found in the following collections \\ Collections

Notes

To request permissions go to:

http://group.bmj.com/group/rights-licensing/permissions

To order reprints go to:

http://journals.bmj.com/cgi/reprintform

To subscribe to BMJ go to:

http://group.bmj.com/subscribe/ 